\title{
Introduction: The challenge. Global injustice and the individual agent
}

The world we live in is unjust. A just world would not feature a distribution of resources wherein a few of the richest people control massive, even increasing amounts of wealth-while large numbers of people live in dire poverty. Nor would a just world feature thousands of people dying every day from unsanitary living conditions, or easily preventable diseases. Nor would so many people suffer oppression, exploitation, and exclusion from the decision making processes that have a significant impact on their lives. A just world would not be one in which nearly all of the women who die as a result of childbirth are from lowand middle-income countries; nor one in which excessive consumption of natural resources in the Global North has led to negative environmental outcomes such as a changing climate severely affecting those living elsewhere, not to mention future generations; nor one in which people seeking to flee war, persecution, deprivation or disaster are often denied access to security, are sent back, or knowingly kept in places where their basic rights are violated. And a just world would clearly not be one in which many of these forms of inequality and injustice, despite of some significant improvement and progress, appear to be on the increase due to such diverse reasons as ongoing unfair trade regulations, rising nationalism and supremacism, ongoing environmental pollution, and so on. This list of injustices reigning in today's globalised world-with its unprecedented international connections and interactions, and movements of people, knowledge, capacities, goods and capital across national borders-could, alas, be further extended.

Obviously, existing political and institutional structures on the national and international level have, so far, failed to address these injustices in an adequate way. The persistence and severity of such inequities in the face of institutional shortcomings thus raise the vexing yet unavoidable question of whether other agents, such as individual people, must step in and do something about them. From the combined perspective of political and moral philosophy, one would then have to ask, what is demanded of individual moral agents given the current unjust conditions of our globalised world? With a narrower focus on a specific group of individuals, the question would be: What should the rather well-off, conscientious citizens of the prosperous countries do about current injustices?

Given the urgency of the challenge and the insufficient responses of institutional agents this question may appear obvious: of course, someone, including individual people, has to do something about these massive injustices. Yet, this answer suggests a perplexing connection between extremely large and com-

Ә OpenAccess. () 2020 Jan-Christoph Heilinger, published by De Gruyter. (cc) BY-NC-ND This work is licensed under the Creative Commons Attribution-NonCommercial-NoDerivatives 4.0 License. 
plex global challenges on the one hand, and the smallest unit of agency, single individuals, on the other. It will be the task of this book to explore the complicated and problematic link between the possibilities of individual agency and urgent need to address global, structural injustices. In it, I reconsider and reassess pertinent normative values, rules and principles that can be deployed to determine the content of individual responsibility in the global context. And I contend that the moral demands for advantaged and privileged individuals like ordinary citizens living in relative security and affluence in the countries of the Global North are more stringent than the prevailing, rather lenient views suggest.

This exploration thus has both practical and theoretical facets. Practically, the question is: What should advantaged individual agents do in the face of massively unjust global structures that clearly favour their material interests and secure their privilege? This practical question, however, turns on a prior, more theoretical one: how should one reason about individual moral responsibility for globally unjust circumstances? The focus of this book on cosmopolitan responsibility will be primarily on the theoretical side and explore and defend from the perspective of moral and political philosophy a possible theory of cosmopolitan responsibility and discuss several challenges for such a theory. Yet, this is done with the conviction that a better understanding can also inform and inspire adequate action and reform.

The distinctive focal point of this book is thus the individual person, seen simultaneously as a needy human being and a bearer of rights on the one hand, and as an active moral agent who is subject to moral demands on the other. As agents, humans are capable of acting with reference to normative concepts, concepts that can also be employed to evaluate the moral quality of a person's actions. Making progress in addressing injustices and promoting justice will, on the side of individual agents, inevitably also require self-scrutiny and a critical examination of one's own life in the social and global context.

The idea of moral cosmopolitanism-i.e. the egalitarian and universalist assumption that each human being is equally morally relevant and that all human beings form a morally relevant community-provides the normative starting point for my exploration of the role and responsibilities of individual agents in the contemporary global context. I will pay particular attention to the attitudes moral agents should develop in response to global injustices if they accept the basic assumption that all human lives are of equal moral importance. This is a normative and pragmatic inquiry into a cosmopolitan, egalitarian ethos, understood as a set of values, norms and concepts that shapes how individuals feel, think, talk and act about global issues in an interconnected world. Such an analysis of the moral and political roles and responsibilities of individual agents in an unjust world contributes to an account of global political ethics, understood 
as a 'bottom up' complement to the 'top down' accounts of global institutional justice. Offering the analysis of individual responsibility as a complement, not a replacement, thus does not curtail the importance of institutional responsibility. Often, only structural, top-down reform-through laws, regulations, financial incentives and penalties and so forth-can bring lasting change. Nevertheless, structural change will not occur unless a sufficient number of committed individuals credibly demand such reform.

Three central ideas that I will explore and defend in this book inform and guide my thinking. First, the extensive degree of interconnection, interaction and interdependency among countries, institutions, and people around the world make it impossible to focus only on the immediate environment of any individual moral agent when assessing the moral quality of any act. While it is uncontroversial to state that the reality of globalisation and the factual 'circumstances of cosmopolitanism' fundamentally shape the contemporary global order, I will argue that cosmopolitanism should feature in our normative understanding of how we as moral agents ought to conduct ourselves within that order, as well. This is particularly important since the advantage of some is frequently connected with the disadvantage of others through the dynamics of structural injustice. Acknowledging not only the reality of the circumstances of cosmopolitanism but also the ideal of moral cosmopolitanism precludes focussing on narrow frames; instead it entails expanding the circle of moral concern to all members of the global order, connected in one way or another-a move that may carry with it dramatic implications for the sphere and content of our responsibilities.

The second idea is that discomfort, indignation, and outrage are appropriate responses towards what appears to count as the "normal," "inevitable," even "acceptable" background conditions of the lives of the well-off citizens in the industrialised, democratic, high-income countries of the Global North. Often enough, the privileged turn a blind eye to unjustified inequalities and structural injustices, consider them to be remote or perhaps regrettable facts of our world, but essentially unconnected to their lives. ${ }^{1}$ Instead of indifference and complacency, a significant, uncomfortable but "healthy dissatisfaction with the familiar" (Nagel 1991, 8) is urgently needed. The presumably normal but dramatically unjust "background conditions" (Young 2006b, 120) of the radically unequal world we inhabit provide a morally repugnant context for all of our actions.

1 While thoughts and actions often positively indicate one's moral values, it is important to consider also what one does not think or do. One's moral convictions are often reflected most accurately by the wrongs and injustices one is willing to overlook. 
This background must be acknowledged to have a bearing on any moral assessment of what we do, as well as of what we fail or refuse to do. ${ }^{2}$

Third, I am persuaded that individual agents and their actions do matter on a global scale, even if global problems and challenges appear overwhelmingly large, complex and numerous. But-as I will argue-individuals have more options than engaging in isolated single acts: they can also become politically active, inform and coordinate with others; they can inspire, call for, and work to bring about collective and institutional change, reform and action that are consistent with cosmopolitan values. This is done best, I argue, by fostering and developing an egalitarian and cosmopolitan ethos to guide one's thought, action and commitment to others in one's potentially global social environment. Ultimately, I do not call for selected transactional contributions to addressing injustice, but for transformational change in how agents think, feel, and respond to it. Indeed, a crucial weakness of the current debate about global justice may well be its failure to sufficiently address the role of individual agents necessary to counterbalance and complement institution-based accounts. After all, the commitments and actions of numerous individuals-ordinary citizens, political activists and official leaders alike-inform and shape existing institutions and the creation of new ones; and, under conditions of institutional shortcomings, ineffectivity or even outright failure, individuals are called upon and become primary subjects of moral demands. These considerations raise rather than diminish the importance and fundamental role of individual agents. Thus, besides political philosophy, moral philosophy has to play a central role in the global context as well. In combining these two dimensions of practical philosophy, my proposed theory of cosmopolitan responsibility ${ }^{3}$ should be read as a contribution to a global political ethics.

Three main theoretical influences shape my proposal: an analysis of structural injustice and its implications for determining the role and responsibilities

2 Injustice is, unluckily, the baseline from which thinking about justice will have to start. Cf. also Shklar (1990, 17).

3 The concept of 'responsibility' itself is rich and notoriously difficult to pin down. Miller has rightly called it "one of the most slippery and confusing terms in the lexicon of moral and political philosophy" (Miller 2007, 82). I agree and only propose a lean understanding of 'responsibility' as the way how individual agents morally ought to respond-cognitively, emotionally and, of course, practically-to a given global issue of moral salience. Responsibility thus importantly includes, but is not limited to, the 'moral ought,' the 'obligation,' the 'duty,' or the 'requirement' that applies to a particular agent in a given situation. For more conceptual work on the notion of responsibility, cf. Hart (2008) and Miller (2007, ch. 4); or the recent fine-grained analysis by Beck $(2016,40)$. As will become obvious throughout the book, my own views about responsibility are deeply indebted to the work of Young (2006b, 2011). 
of individuals in this context in the tradition of Young (2011); relational theories of equality (Scheffler 1993, Anderson 1999, Scheffler 2015), deployed in a modified form to explore the nature of moral obligations that extend beyond the domestic frame to the global scale; and pragmatic accounts of ethics and their assumptions about normative pluralism, the importance of habits and social dynamics, and the possibility of moral and social progress (Dewey and Tufts 1932, Dewey 1939, Kitcher 2011).

\section{The 'circumstances of cosmopolitanism'}

In the past, most human beings lived without detailed knowledge about (or even an awareness of) different cultures in far away regions. Today, by contrast, only few human beings remain detached from the forces of global communication, trade and politics. Indeed, the contemporary world, more than ever before, is characterised by a dense set of intensive connections and interactions among individuals and institutions very nearly everywhere (Widdows 2011; 5, 271). Moreover, even those very few with little or no direct exposure to the modern technological world are now nonetheless affected by it, notably through diffuse phenomena such as environmental pollution and climate change. Even isolated, non-industrial societies living deep in uncharted areas of the Brazilian rainforest, for example, cannot escape the consequences of changing weather patterns. The consequences of global trade, furthermore, affect local markets even in the most remote areas of the world, as the aggregate effect of global consumerism leaves virtually no producer or consumer untouched; global trade and ruthless economic competition have resulted in the creation of "special export zones," in which workers manufacture often trivial consumer products under inhumane conditions; intellectual property regimes prevent access to essential medicines; famines are aggravated by financial sector speculation on staple foods; illicit financial flows and off-shore business encourages tax evasion which prevents poorer and richer countries alike from providing essential services to their citizens. There are also global events like the soccer world cup that do not only bring people together by providing sports-centered entertainment to a truly global audience. They also create a sphere of global publicity that triggers political discussions ranging from the management of the tournament by its organising institutions, over the diversity of the teams mirroring the history of the country, to the political situation in host countries and the often fraught political relationships between countries.

Global interconnectedness and interdependence has reached historically unprecedented levels; it has brought about institutionalised forms of interaction of 
states and international bodies that cover communication and media, the rules and practices of both local and global business, and people's leisure activities, travelling, consumer preferences and choices. Such connections, relations and interactions have such a massive and pervasive impact on the lives of peopleboth positive (advantageous) and negative (limiting) - that they have effectively become unavoidable, as it is neither possible to escape them, nor to be unaffected by them. They are also in an important sense non-voluntary, since no one was asked or able to give prior consent to being subject to such global dynamics. The extensive connections between states, institutions and individuals are thus an inescapable fact, which I call the de facto circumstances of cosmopolitanism or the existing global order (even though I do not mean to insinuate that it is particularly well-ordered). The circumstances of cosmopolitanism are constituted by the multiple, inevitable and highly significant connections between people around the globe.

However, the last decades have also brought about many remarkably successful interventions and enlightened developments-even though no achievement is immune to challenges and potential failure. Supranational structures like the United Nations and the European Union continue to evolve to better defend universal rights and basic standards for the treatment of all people (albeit not without an abundance of conflict and new challenges) via the proclamation and progressive realisation of the goals of various instruments such as the Universal Declaration of Human Rights and the Sustainable Development Goals. As a result of such developments, for example, a smaller percentage of the world's population lives under conditions of severe poverty today than at any time before. ${ }^{4}$ Strides are also being made in cooperation to combat climate change, with the results of the COP21 meeting in Paris in late 2015 being something of a breakthrough for being at least partially legally binding-even though the current global political climate at the time of writing these lines poses significant new threats to the achieved agreements.

In fact, despite some progress, existing institutions and patterns of interaction have yet to achieve substantial and enduring improvements for the billions of people who continue to live in extreme deprivation and/or continue to be unjustly dominated by others. This type of injustice, as Iris M. Young characterises it, and the morally alarming persistence of the unequal distribution of new benefits and costs, qualifies as an instance of structural injustice (Young 2011). It takes a very particular form:

4 Cf. e.g. https://ourworldindata.org [last accessed: 1 July 2019] or Pinker (2011) and Deaton (2013). 


\begin{abstract}
Structural injustice exists when social processes put large categories of persons under a systematic threat of domination or deprivation of the means to develop and exercise their capacities, at the same time as these processes enable others to dominate or have a wide range of opportunities for developing and exercising their capacities. Structural injustice is a kind of moral wrong distinct from the wrongful action of an individual agent or the willfully repressive policies of a state. Structural injustice occurs as a consequence of many individuals and institutions acting in pursuit of their particular goals and interests, within given institutional rules and accepted norms. (Young 2006b, 114)
\end{abstract}

It is important to emphasise that this disadvantaging of a sizeable proportion of humanity is the collateral result of many agents acting in ways that have been and continue to be widely considered "normal," "legal," and even morally unproblematic, such as the powerful pursuit of national interests by political leaders and the pursuit of personal interests by already advantaged individuals. ${ }^{5}$ Alas, this does not alter the fact that repeated patterns of presumably unproblematic and permissible behaviour within established structures not only secure privilege and advantage but ultimately lead to and perpetuate negative outcomes for vast swathes of humanity. A massive proportion of human disadvantage is not the result of unavoidable causes (like natural disasters), but is anthropogenic, in the sense that it is socially and politically constituted, or could-through coordinated effort-be avoided. Hence, human beings and the social structures they bring about are at the origin of the ongoing disaster of structural injustice in the world.

Acknowledging these 'circumstances of cosmopolitanism'-including the disastrous global outcomes of structural injustice, created and maintained by normal practices widely regarded as acceptable-is not easy for those enjoying the advantages of security, political stability, and economic prosperity. ${ }^{6}$ Such acknowledgement would compare and link-partly through a factual, causal connection through interactions; partly through a conceptual connection through the ideal of the equal moral standing of all-the advantages of some with the disadvantages of others. But then, as Nagel has formulated pointedly: "The magnitude of the world's problems and the inequality in access to its resources produce a weight of potential guilt that may, depending on one's temperament, require considerable ingenuity to keep roped down" (Nagel 1986, 190). Yet,

5 Of course, there are also malevolent and ruthless disruptive interventions by political and public figures, institutions, and individuals, that aggravate existing or trigger new injustices. 6 Dewey also acknowledges this: "It is difficult for a person in a place of authoritative power to avoid supposing that what he wants is right as long as he has power to enforce his demand. And even with the best will in the world, he is likely to be isolated from the real needs of others, and the perils of ignorance are added to those of selfishness." (Dewey and Tufts 1932, 226). 
most of the rather well-off citizens of affluent countries seem to muster that ingenuity with ease, so that they live their comfortable lives more or less unaffected by feelings of complicity with or responsibility for the unjust structures that enable or perpetuate their privilege. The core challenge put forward in this book is to make some progress in understanding the role and responsibilities of individuals in light of the disastrous background conditions just described.

\section{The idea of cosmopolitanism}

A guiding normative idea of this book is to understand human beings as "cosmopolitans", as citizens of the world. The fact that all human beings today live in a highly interconnected world makes them, nolens volens, members of a jointly shared system of interaction: everyone is a member of the global order (even if, once again, its dysfunctions and inherent structural injustices make the use of the term "order" here rather less than a literal one). First developed in early Greek philosophy, the idea of "world citizenship" designated the very idea that all human beings are bound together as equals in spite of the differences between groups and individuals and jointly form a morally relevant community. Initially largely idealistic, the increasing interconnections across the globe today have made it more obvious than ever before that there is indeed some form of a factual global sphere of mutual influence and community of which all human beings are members. A moral account of cosmopolitanism is hence based on two assumptions: that each human being is of equal moral standing; and that the morally relevant community includes all humans. This ideal can be used to assess states of affairs from a normative perspective, and to morally demand particular acts and institutional arrangements: It first states the interconnected global reality (circumstances of cosmopolitanism); it then diagnoses several moral flaws in the current global order, based on the moral view that, even in the absence of an actual world-state, every member of the human community is entitled to being respected and treated as a moral equal; and it then assigns cosmopolitan responsibilities to individual and institutional agents.

Unlike other contributions based on the cosmopolitan commitment to equality and universality, my focus here is not so much on giving detailed advice about concrete practices and actions of individuals (e.g. Singer 2009), nor on an analysis of the political dimension of cosmopolitanism (e.g. Hahn 2017) or specific recommendations for institutional reform (e.g. Wenar 2016, Neuhäuser 2018, Cabrera 2018). Instead, I will take a step back and approach cosmopolitanism as a distinctive big-picture moral outlook with implications for the morally demanded underlying ethos that should inform an individual agent's feelings, 
thoughts, and actions. This approach is based on the idea that it is possible to promote and implement the cosmopolitan ideal not only from top down but also from the bottom up: cosmopolitanism can then start being realised 'within borders,' such as in an agent's direct, local sphere of influence or in one country or a federation of countries that are willing to take a lead. ${ }^{7}$ Individual agents can integrate global thinking into their local action; and institutional agents can already respect their global responsibility in their confined sphere of influence.

\section{Towards a global political ethics}

The ongoing scholarly debates about global justice are rich and manifold. They include normative discussions about the existing global institutional order, about the establishment and regulation of fair trade relationships between nations, about corporate social responsibility of multinational companies, about what constitutes a just distribution of benefits and burdens between different global players, about the conditions for just war, and about possible limits of state sovereignty, particularly with regard to the control of borders, but also with regard to the right or duty of states to intervene to assist citizens in other countries, regardless of sovereign prerogative or cost to the intervening countries (cf. e.g. Brock and Moellendorf 2005, Brock 2013). These are very important debates. Most of the participants in these debates, however, adopt Rawls's lead ${ }^{8}$ in largely ignoring the role of the individual when it comes to matters of justice, which he initially proposed could only be an emergent feature of the political and social institutions of a liberal society. According to Rawls, justice is "the first virtue of institutions" (Rawls 1999b, 3), and the individual is, as a result, accorded only a minor role in his theory of justice. A similar marginalisation of the role and responsibility of the individual has dominated the debates about global justice.

It is not that I object to a focus on institutions or states in the debate about (global) justice. It is clearly appropriate and necessary to elaborate on institutions, interstate interaction and global structures, especially when these are causally implicated in the generation and maintenance of structural injustice and

7 Cf. e.g. Wild and Heilinger (2013).

8 While they follow Rawls in this regard, the extension of the scope of justice from the domestic to the international realm is a modification of the Rawlsian doctrine, which limited talk of justice to the sphere of the nation state (Rawls 1999). My own view thus differs from Rawls's theory of justice in two ways: First, I dedicate more attention to individuals as agents of justice; second, I assume the scope of justice is global. 
where institutional reform constitutes the most effective, maybe even the only way to eventually overcome structural injustices. But Rawls notwithstanding, it must not be ignored that, ultimately, institutions are not "natural kinds" existing independently of human beings. Instead, they are created by people, frequently with the intention to better fulfill what they deem to be important tasks. Ultimately, individuals shape institutions and social structures, and continue to fill them with life and spirit-for better or for worse. This, in turn, implies that the ethos of people-i.e. their normative commitments and ambitions that shape their dispositions and habits of feeling and thinking, talking and acting -has a significant impact on the existence and functioning of institutions. Individuals also exercise influence on the social norms that govern behaviour and on the (politically and morally relevant) ideas that exist in a group.

Thus, I suggest to direct, in questions about global justice, particular attention to the potential role of individual moral agents, and both the direct and the indirect effects of their behaviour. ${ }^{9}$ This will, I contend, open potentially fruitful avenues for analysing their responsibilities and guiding their attitudes and actions. My inquiry into the role and responsibilities of individual moral agents in an interconnected, unjust world is not meant to replace, but to complement debates over global institutional justice. It brings into consideration this neglected level of global political ethics, the level of individual agency. It requires individuals to accept responsibility, acknowledges and discusses challenges, but concludes with empowering arguments for the importance of individual engagement under current conditions of injustice.

Even though the focus of this work is clearly on the individual's role in the face of global injustice, I do not mean to imply that comprehensive solutions to global injustice are likely to flow from isolated instances of individual action alone. Cooperative and collective action, and a smart division of the moral labour, ultimately involving institutional agency in the right way, are still necessary. However, all agents are also individually subject to moral demands, and bear personal responsibility to promote the changes necessary to fight existing injustice and advance egalitarian justice globally. In the absence of adequate institutions and in the absence of an ethos of cosmopolitan responsibility, the chances for genuine egalitarian progress appear limited, even grim. But individuals can start and continue making a credible case for change and reform to promote justice; they can, through their acts, also inform and influence others, and this is the best possible way forward for individuals to contribute to addressing and possibly eventually overcoming the massive wrongs that dominate our world.

9 Cf. also Young (2011, 73), Cohen (2008) and the concluding chapter below. 
Such individual dispositions matter particularly in time of crisis where suddenly the established order and patterns of conduct are questioned and become fragile. The ideas that are in the air at a time of crisis can then be taken into account, guide action, inspire and inform reforms and thus shape the future. It is the important task of individuals to keep the right ideas alive and available, especially under adverse conditions, so that they are at hand when the opportunity arises to deploy and implement them on a larger scale.

\section{The pragmatic impulse}

The ideas expressed in this book take up several impulses from the tradition of US-American pragmatism, found notably in the writings of Dewey. Most importantly, a pragmatist perspective on ethics emphasises a moral outlook characterised by three elements that I take to be central to my task: an emphasis on the individual agent (and his or her habits) in social contexts as the core concern of morality; preference for a pluralist method of moral inquiry over the defense of any narrow set of criteria, principles or conclusions; and a resolute optimism that moral and social progress is possible.

Many current global issues-such as inequality and world poverty, climate change and the unjust dynamics in the global economy-are also distinctively moral challenges resulting from and influencing the actions and experiences of persons. It is the habitual actions of individual agents, the things we do day after day (including seemingly trivial consumer decisions or travel preferences), that are at the root of many global problems related to structural injustice. ${ }^{10}$ Morality, in the pragmatist tradition, stresses the importance of constantly evaluating, re-evaluating, and intentionally shaping our habits, based on moral insight drawn from the full spectrum of sources, rather than from any single normative theory, which, for Dewey at least, would be too limited to be of much practical service. Moral decision-making is complex and multi-faceted, both for individual agents considering their obligations, and for answering the questions of what better political and institutional arrangements would look like, and which actions are likely to help bring about such arrangements. My approach is focussed on the careful cultivation of appropriate habits as a method for ongoing

10 At another level, of course, the repeated and unquestioned preference by politicians and decision-makers to prioritise the gains of themselves and their communities with no regard to the costs imposed on others, plays a particularly influential role. 
practical reasoning, moral decision making, and action about the current global challenges.

Following Kitcher (2011), I regard reflections about all forms of individual ethical conduct to be inherently embedded in the larger "ethical project" of living together in an ever larger, now truly global community of human beings on this planet. I contend that the ideals of cosmopolitan responsibility must ultimately translate into "a personal way of individual life" in light of the reality and nature of globalised human relations. Such a "personalisation" includes:

the possession and continual use of certain attitudes, forming personal character and determining desire and purpose in all the relations of life. Instead of thinking of our own dispositions and habits as accommodated to certain institutions we have to learn to think of the latter as expressions, projections and extensions of habitually dominant personal attitudes. (Dewey 1939, 226)

Such an account invites a politisation and "ethicisation" of daily life, a change from the assumed innocence and amorality of ordinary behaviour. While it does not require us to be always and exclusively concerned with moral considerations, it charges all our actions with an ethically relevant dimension. Yet, pragmatic ethics does not stop with such a focus on individual agency: it points to the need to structure the political and social environment in a way that it both reflects the considered normative commitments of people and facilitates individual behavior that aligns with these commitments. Individual behaviour thus has a public and political dimension; and democratic structures inform and shape individual behaviour. Making intelligent use of these dynamics thus can facilitate moral and social progress in the form of structural change.

\section{Overview}

This book confronts the pressing question about the role and responsibility of individual agents in an unjust world. I consider this to be among the defining moral, political and philosophical challenges of our time. It would be folly to suggest that a single book, let alone this one, could once and for all settle such an issue. Instead, I only hope to offer some routes for morally reflective individuals to consider as they attempt to navigate the difficult terrain surrounding the question of how to act in the face of global structural injustice.

With this aim, the book proposes a theory of cosmopolitan responsibility to analyse and determine the role and the responsibility of individual agents in the context of global structural injustice. This theory lies at the intersection of moral and political philosophy and can be called a global political ethics. Con- 
cretely, it consists of an account of a cosmopolitan ethos, i.e. a set of ideas, values and commitments that can shape how individuals feel, think, talk and act about global issues in the local context they find themselves in. This cosmopolitan ethos, with its three central elements-the idea of world citizenship; a commitment to global relational egalitarianism; and a pragmatic understanding of ethics, action and habit-is presented in part I. The ethos is elaborated further in part II with the help of three important challenges that can appear once one starts weighing options for action out of the cosmopolitan ethos: the problem that individual acts may be too small to generate any relevant impact on global issues; the tension between universal obligations towards all and special obligations towards some particularly near and dear to us; and the danger of inevitable failure because cosmopolitan obligations exceed what is humanely possible.

Chapter one offers a historical and conceptual overview about the idea of cosmopolitanism in its different diagnostic and normative forms in Western philosophy from antiquity to the 20th century. While the first half of chapter one is more historical, the second half introduces important contemporary concepts and discussions, such as about the scope of justice, the universalist and particularist poles of the debate, different metrics and patterns of justice, and the notion of structural injustice. It concludes with an outlook on global political ethics with reflections on the relationship of individuals and institutions, the division of labour in society, and the possibility of fostering an egalitarian ethos.

Chapter two considers the basic notion of equality that lies at the heart of the present analysis. I compare and contrast distributive and relational accounts of egalitarianism, both on the domestic and the global level. Ultimately, I argue for global relational egalitarianism as the best account to capture the fundamental commitments of cosmopolitan responsibility. This view understands equality as a lived practice, something we $d o$, not as a static state of affairs or pattern of distribution. It demands, negatively, that oppression, domination, exploitation, marginalisation, exclusion, etc. have to end; and it demands, positively, that equality must reign in all possible and actual interactions and relationships. This understanding of the ideal of equality also has normative implications for individual behaviour and will thus inform my further arguments about the way how individual agents should respond to issues of global inequality and injustice.

Chapter three brings into relief some impulses from the philosophical tradition of American pragmatism which underlie and inspire my account of cosmopolitan responsibility, such as the possibility to integrate normative values into the individual and collective "way of life", the importance of habits over single acts, and an optimistic belief in the possibility of social and moral progress. Pragmatism also assigns philosophy a modest but constructive role in address- 
ing problems and identifying solutions to facilitate and improve the living together of all.

In advancing the moral ideal of cosmopolitanism, the theory of global relational egalitarianism and the pragmatic perspective, part I will provide the normative groundwork for my theory of cosmopolitan responsibility that can be integrated in the personal ethos of individual agents.

Part II moves on to weighing action. Its three chapters discuss three pressing challenges that arise once agents endorse and attempt to act out of the cosmopolitan ethos, presented in part I. How does individual action matter? Does cosmopolitan responsibility leave room for any preferential treatment of those particularly near and dear to us? And: Can we ever hope to live up to the apparently excessive demands of cosmopolitan responsibility?

Chapter four addresses the tension between the large size of problems of global injustice and the inevitably very small impact of individual agency: Given this discrepancy, any agent weighing different reasons for action will wonder whether her actions will matter at all; and whether they will be able to generate any meaningful impact. The chapter discusses several ways in which even single acts of individual agents matter morally: as small contributions to large harm; as small triggers that can set of a cascade of events; or as contributions that (even if they make only a negligible difference to addressing a complex global problem) make a very big difference for some who are affected by a complex global problem. To conclude, the chapter introduces Young's social connection model to explain how not only single acts, but particularly repeated patterns of individual action matter in contexts of structural injustice. It identifies several criteria that can help determine the content of individual responsibility. The results reached in this chapter will be taken up and expanded further in the concluding chapter of the book.

In chapter five, I address the puzzle of partiality, an important and practically relevant objection against an account of cosmopolitan responsibility. This puzzle is based on the tension between universal, impartial demands on the one hand, and partial, more immediate demands on the other. This challenging tension becomes palpable once individuals consider everyone as a being of equal moral standing, while still feeling a special commitment or obligation towards some that are particularly near and dear. This tension is difficult to solve: even if impartiality always matters morally, it clearly is not all that matters morally. The chapter discusses the grounds for special obligations and preferential treatment for oneself, for one's intimates, and also for one's compatriots. I argue that relationship-dependent reasons for preferential treatment, as they result from personal connections, have some genuine moral weight that can render some degree of preferential treatment morally permissible. Membership-dependent rea- 
sons for preferential treatment, however, as they result for example from shared nationality, cannot claim to have similar moral force: if not all have equal access to the relevant communities, that are not shaped by close interpersonal relations, preferential treatment of the in-groups comes at the morally unjustifiable expense of those who are excluded.

However, even in the case of well-justified and permissible forms of preferential treatment within special relations, the universal and impartial reasons can never be fully eliminated. Thus, a tension between the two incommensurable standpoints of partiality and impartiality will inevitably persist, at least under conditions of massive inequality. Consequently, morality as such does not appear as an integrated and comprehensive whole but as a fragmented set of competing perspectives and values, that renders the possibility of successfully navigating through mutually exclusive demands dubious.

Chapter six pursues this insight further by addressing the moral overdemandingness objection: cosmopolitan responsibility might generate impossible moral requirements if, under current conditions, weighty and non-negotiable moral requirements (that are able to pass an interpersonal justification test) bind agents, no matter whether they are actually capable of acting upon them. The chapter critically reviews different possible strategies to ease the moral burden that results from a cosmopolitan extension of moral concern. But arguments for reducing the moral burden of individual agents to what they consider not excessively demanding and/or feasible is not the only option. Alternatively, one could accept that it is impossible, under current conditions of extreme inequality and injustice, to live a fully moral live. In the second half of the chapter I explore and defend this second option, however much more controversial and much less appealing it may be. Yet, taking the needs and unmet basic rights of the disadvantaged seriously deserves priority over worrying about the moral innocence of the advantaged. Thus, I propose a qualified account of impossible moral imperfection, even failure, that distinguishes its objective, diagnostic dimension from its subjective and intersubjective dimensions. Generally, it should not count as a flaw of any (sufficiently demanding) moral theory if it places apparently excessive moral burdens on those who could, in principle, act. Instead, such overdemandingness rather indicates a flaw of the world that needs to be corrected.

The critical reflections of part II-on the limits of individual agency in a global context, on the puzzle of partiality and on moral overdemandingnesselaborate my understanding of the role and responsibility of individual agents in the face of global structural injustice: As morally equal citizens of the world, agents aspire to contribute to realising global relational equality. Committed, from a pragmatic persepective, to normative pluralism, and equipped with a firm belief in the possibility of progress, they understand that their direct impact 
will inevitably be limited. But even apparently tiny contributions might matter, particularly if they are repeated over long periods of time and if they start to spread, influence behaviour of others, shape ideas and consolidate themselves in institutions. Clearly, the social and epistemic networks that today connect people across the globe will not only impose limits to unconstrained preferential treatment for oneself and for those particularly near and dear; it will also make moral perfection unavailable under current conditions. But acknowledging these unpleasant realities can motivate responsible cosmopolitan agents to take pride in contributing-through concrete and often local action out of global thinking-to realising a world in which the circumstances are such that global structural injustice ceases to exist; in which everyone's basic needs and interests are fully met; and in which, consequently, preferential treatment for some becomes less problematic and moral failure, in the sense analysed, can be avoided.

In this spirit, the book concludes with a chapter on the ethos of cosmopolitan responsibility. The adequate response of individual agents to global injustice consists in developing an egalitarian, cosmopolitan ethos that informs and influences one's way of feeling, thinking, talking and acting about injustice. Given the pervasive nature of global structural injustice, promoting an egalitarian ethosin individuals and groups-would be, I contend, a suitable contribution to addressing the distinctive wrong of pervasive structural injustice from the side of individuals. An ethos links the cognitive-rational, the socio-emotional and the dispositional-behavioural dimensions of a person and thus does not only trigger small direct ('vertical') action to address injustice; it also generates indirect ('horizontal') effects by communicating one's moral and political commitments to other agents in one's community. No individual in isolation can have a meaningful impact upon the massive and complex challenge of global injustice; but joint normative commitments, shared aims, and coordinated political and systemic action, of which individuals can be part, can generate impact and bring reform.

As I argue throughout the book, a major shift in perceiving the wrong of injustice is necessary: global problems have to be moved from the periphery of our attention more to the centre; and they have to be conceptualised as challenges that must not be left to ineffective or inexistent institutions: they require responses from individual moral agents, too. Fostering an ethos of cosmopolitan responsibility with its pervasive impact on how agents feel, think, talk and act does just this.

Of course, for those seeking specific guidance about what to do, my account of cosmopolitan responsibility will most likely appear insufficiently concrete. And obviously, a great number of questions remain unaddressed and unanswered in the following pages. But the goal of my philosophical analysis is-in spite of its ambitious scope and its firm conviction that promoting a cosmopolitan ethos is 
urgently needed-quite modest: to engage in a conceptual inquiry into the values, norms and principles that can determine and help guide individual responsible action in the global context. Thinking through the issues presented in this book will hopefully provide readers with some thought provoking material to form their own judgements about what to do and then to take responsible action, once that the importance of individual contributions to respecting the equal moral importance of all and to addressing global wrongs has been firmly established. 
